\title{
Building Professional Communication Skills InSide AND Outside Formal Educational ConteXts: The Challenges AND OPPORTUNities Of ENgineERING CO-OP PlaceMENTS
}

\author{
Cristina Fabretto \\ Memorial university of Newfoundland \\ fabretto@mun.ca
}

\begin{abstract}
The addition of a co-op component to a traditional academic curriculum creates a unique challenge for those international students who enter the program without a strong command of the English language and with insufficient familiarity with the professional context. This paper investigates that challenge as it relates to the international students enrolled at a Canadian Bachelor of Engineering co-op program. Currently adopted pedagogical practices are reviewed and an argument is introduced for alternative strategies and solutions to be devised so that academic and professional success is attainable for all students.
\end{abstract}

Keywords: Communicative competence, situated learning, co-op programs, international students

\section{INTRODUCTION}

A growing body of research in engineering reports employers calling upon faculties to produce graduates that are professionally ready to enter the industry immediately after graduation $[1,2]$. Recent years have seen the growth of co-operative programs in faculties of engineering across Canada. Mission of these programs is to equip undergraduate engineering students with some direct experience in the professional world they expect to enter after graduation. Importantly, co-op programs aim at familiarizing learners with the practices, norms, and rules of the engineering professional community. They facilitate the acquisition and development of relevant professional skills necessary to function successfully in the workplace. Increasingly, professional skills developed during the work term have become instrumental for students' post-graduate employment. Research shows that engineering undergraduates' work-term experience has a considerable positive effect on graduates' likelihood of receiving a job offer prior to graduation and a considerable increase in starting salary. This paper draws from a case study research which considered the professional skills relevant to employment in the engineering sector in the context of a Canadian undergraduate co-op only Bachelor of Engineering Program at a Canadian university. However, unlike mainstream research that studies professional skills as an outcome of a successful co-op program, here they are considered as a prerequisite for it.

Specifically, this paper is centred on non-technical communication, as the skill that researchers and employers regard as a core requirement of the engineering profession [3-7]. Furthermore, aligned with current and projected demographic trends nationwide, investigative focus is placed on how communication relates to co-op placements when the student candidate is international. It is established that most international students struggle [8, 9], in some way and to some extent, to function and integrate in their new host-country and to succeed in their academic program [10-14] using a foreign language [1518]. Their struggle is more evident among first year nonnative speakers. Insufficient language ability and unfamiliarity with postsecondary teaching and learning tradition pose significant challenges to this cohort when enrolled in a co-op only B.Eng. Program. Nevertheless, findings from the study show that domestic students and native English speakers too often struggle securing a work placement due to inadequate communication ability.

Completing several work terms, in different roles at increasing degree of seniority, makes it possible for the student to reach graduation with a sufficiently strong and diversified knowledge repertoire to compete for graduate employment. Other studies have confirmed this [19, 20], which accounts for the proliferation of co-op engineering programs in Canada, North America, and around the world [1]. The mission of these programs is to equip undergraduate engineering students with some direct experience in the professional world they expect to enter after graduation. Through work terms, co-op programs provide an opportunity for students to apply the technical know-how acquired in class to real life problems. Perhaps more importantly, these programs aim at familiarizing learners with the practices, norms, and rules of the engineering professional community. They facilitate the acquisition and development of relevant professional skills-commonly referred to as soft skills in other fieldsnecessary to function successfully in the workplace. Increasingly, professional skills developed during the 
work term have become instrumental for students' postgraduate employment.

As Schuurman, Pangborn, and McClintic [21, 22] argue, engineering undergraduates' work-term experience has a considerable positive effect on graduates' likelihood of receiving a job offer prior to graduation and a considerable increase in starting salary. Specifically, results from their studies indicate that the number of work experiences is positively correlated with early career success, making work-term placement an important way to maximise students' employability. While, as a sector, engineering is constantly expanding, it is also very competitive. High competition characterises also the recruitment of engineering students for work term placement. To investigate why some international students succeed, while others fail, is to explore what recruiters and employers expect of them. Accordingly, investigating where most students struggle, and some stumble, identifies gaps and deficiencies in their preparation that the program has either overlooked, or has been unable to solve.

\section{METHOD}

The research underpinning this study was designed as a single embedded exploratory case study [23] with communication for work term placement as the unit of analysis. As Yin (2009) defines it, a case study is an empirical inquiry that investigates a contemporary phenomenon within its real-life context, when the boundaries between phenomenon and context are not clear. The choice to employ an exploratory case study was supported by the observation that the knowledge base of the topic was poor, and the literature provided no suitable conceptual framework or hypothesis of note (Yin, 2009). For the purpose of that study, semi-structured interviews were designed and adapted for each of the four groups, beginning with engineering international students, followed by representatives from the industry, namely coop students' recruiters and supervisors, and, lastly, with FEAS co-op coordinators and university staff. The aim of the semi-structured interviews was to promote a freeflowing conversation between interviewer and participant, as best suited for an exploratory approach to a research topic [24]. Results were grouped by source, and verbatim transcripts of the interviews were coded using Constant Comparison Analysis [25]. The overarching question investigated why some international students succeed, while others fail, in securing a work term placement and the role that the job candidate' quality of communication has in determining the outcome. By investigating success and failure, the aim was to uncover the true impact that poor communication has on a student securing a work term and completing it. Whether and to what extent communication is a factor in the type of placement for which students are hired is also contemplated. Furthermore, an important purpose of the interviews was to reveal the recruiter and employer's expectations of the candidate in terms of communication, bringing to light potential gaps and deficiencies in students' preparation. Lastly, a more practical question worth asking is how can the language and intercultural needs of the students be accommodated within existing resources, inescapable constraints, but also established pedagogical traditions.

\section{RESULTS}

Results point at a significant lack of clarity and direction surrounding how students are introduced to the concept of professional communication and to its critical role in work term placement. This suggested the need for greater structure in the way communication is approached at faculty level. The way in which recruiters and employers' expectations are currently addressed is unsystematic and devoid of necessary details required for the satisfactory development of competence. Also noteworthy is the potential ineffectiveness of competence building pedagogical practices intended to develop relevant professional communication competence. Exacerbated by the increase in diversity within the student population, these practices are, in some cases, counterproductive, leading to consequences opposed to those initially intended. The need for greater transparency, consistency, continuity, and accountability of learning and progress call for alternative approaches.

\subsection{Transparency and Consistency}

Despite the considerable support provided, findings suggest that many students feel ill-prepared to face the work term challenge because they do not know what is expected of them in terms of communication competence. As reported by recruiters, those who stumble do so because they seem not to know what they are doing. Industry representatives interviewed suggest that much improvement is necessary in the developing of students' awareness and knowledge of the link between communication, co-op selection protocols, and on-the-job success. Those who struggle with uncertainty likely do not fully grasp the concept of context as it relates to language use in real-life situations [26-28]. Students transitioning from academic to professional roles do not always fully appreciate the critical changes that are required of them. They fail to grasp the implications of that transition on their communication requirements. This is a critical oversight that accounts for many of the unfulfilled aspirations of any number of well-intentioned students, who ultimately approach their work term unaware that they are ill-prepared and unequipped to meet employers' expectations. 
The adoption of standardised tests for international admissions into the program further exacerbates this situation. Findings from this study confirm what researchers have been disputing with regard to the overall reliability and effectiveness of standardised English language tests currently used to screen international university applicants [29-34]. Specifically, findings point also to the inherent limitations of such tests for estimating students' language ability in non-academic settings. As a result, international students may be operating with a false sense of security regarding their ability to communicate because they assume that their language ability is sufficient for completing both the academic and the professional component of their program. Analogously, the faculty may be accepting the competence attested by the standardized tests results as a sufficient base on which students can build their competence while in the program.

Success in a co-op program requires a much higher level of competence than a traditional academic engineering program. For this reason, international students who succeed academically, sometimes fail professionally. Faculties may overlook the potential implications that lack of clarity and explicit direction on such a critical point have for new international students. Furthermore, in line with Philpott et al. [35], this research confirms that ambiguity persists during the entire first year of the program. As a result, international students are often unaware of potential lacunae in their preparation until it is too late, that is until they enter their first work term competition. Greater clarity needs to replace nebulous and ambiguous descriptions of students' professional communication as articulated in the engineering literature and at faculty level, with much clearer industry standards.

Preparing graduates to enter the profession as effective communicators entails monitoring quality and progress of students' competence in communication from admission to graduation. Consistent with existing literature [36-42], a study conducted at Memorial University on work term recruitment of international engineering students reported that good communication skills are consistently highly valued by employers yet frequently poorly developed by international students, particularly, yet not exclusively, at the junior level. Findings also revealed that domestic students are increasingly found to be ineffective communicators in professional settings along the same lines as many international students. The general language and communication skills of enrolling domestic students are assumed to be present. Those of international students are assumed to be adequate, being certified by Universityapproved admission standardized tests (e.g. TOEFL, IELTS, CAEL). Yet the number of cases that defy these assumptions is high and growing. The need emerged for an assessment instrument that would guarantee fluency in the workplace, by targeting real-life English language demands of the co-op engineering profession in Canada. The lack of options available that would fit those requirements supports the argument for the development of a tailored framework of reference rigorous yet flexible to adapt to the need for progress of learners in the contexts of use along the program continuum leading up to graduation.

\subsection{Continuity and Progress}

In a co-op program, progress should be viewed as occurring in two main stages along the undergraduate curriculum. The first stage covers the expected progress from enrolment to the first work term competition. The second, extends beyond that point and ends at graduation. In both stages, each work term requires that the student performs in progressively more demanding professional contexts and situations [43], relevant to the job or the role for which one applies, and the hiring company [44-47]. One's ability to communicate is understood as evolving along a hypothetical continuum from enrolment to graduation, from incompetence to mastery, and the criteria for effectiveness are job- and context-specific. Being a good communicator in one context does not guarantee ability in another context. Individuals may be stronger in one or more of the four language skills (speaking, listening, writing, reading) or in one of the areas of competence in which professional communication often takes place (interaction, information, instructions, persuasion). The analysis of professional communication needs to be built on the premise that in each co-op competition and placement students communicate in a range of real-life professional scenarios and contexts that vary based on the type of job and the student's level of seniority.

Furthermore, progress occurs in an unstructured and unpredictable way. Several factors inhibit or facilitate progress. Different roles generate varying opportunities for social interaction and professional exchange. As a result, not all students are afforded the same opportunities to grow. Findings from the research suggest that students who are weaker communicators are oftentimes hired for less interactive jobs. Interviewees observed that students who are good communicators usually receive offers from the best companies for positions that are personally stimulating and professionally enriching. Conversely, the worse communicator a student is, the greater the likelihood that the hire is for a more technical positions, often to be carried out in relative isolation, with fewer opportunities for learning and improvement. The quality of the trainee-supervisor rapport as well as the presence of a mentor in the learner's life can have significant impact on the quality of a learner's communication. 
Failing to secure a good work term placement has shortand long-term implications for the student. Despite being allowed to graduate, having completed the mandated number of work terms, some students may be entering the profession with a significantly less developed communication competence than some of their peers.

The educational value of a work term must be collocated in this perspective. Some of the students interviewed as part of the research indicated that they considered their co-op experience as educationally valueless. Others, on the other hand, described themselves as being immersed in a learning environment that was conducive to learning [48-50], in a work environment organised to be a "learning community" [51] where opportunities to employ and develop professional communication abound [52-55].

In discussing professional communication in an engineering education perspective, researchers argue that becoming an effective engineering communicator involves shifting from envisioning communication as purely, or almost exclusively, technical to seeing it as socio-technical [56]. It entails mastering the economic, environmental, ethical, political, organizational, and interpersonal- hence intercultural- intricacies associated with the engineering profession. Research suggests that this can only be achieved after several years of industry experience. It is during that time that one acquires the practices, norms, and rules of the engineering community necessary to function successfully in the profession. Novices develop the communication competence relevant to a particular professional community (i.e. a community of practice) by interacting with its more experienced members. It is a rather organic and individualized learning process. Viewing learning as heavily dependent on interaction, rather than traditional instruction, makes the learner uniquely accountable. A process of development that is independent from formal instruction, and depended on social interaction, puts the learner at the centre of the learning process. That is because the development of competence is associated with one's actions and interactions in formal, non-formal, and informal day-to-day professional events and activities.

\subsection{Accountability}

Work-terms are supposed to facilitate acquisition of professional skills [1]. By placing the student in the context of the profession, the expectation is that the student will acquire the skills employers demand and develop the professional habits of their supervisors and other role models [1]. Put broadly, students are socialized into the professional community [57]. Their communicative competence [58] strengthened as a function of social interaction with more experienced, more proficient, or "expert", members of that professional community. Thus, they develop competence in communicating within the community context unique to their workplace. Students learn the socially appropriate communication practices of that community and begin their journey from the 'periphery' of knowledge as novices towards becoming central members of that community [59, 60]. As many researchers [56, 61, 62] argue, to an extent all engineering learning is situated learning. By privileging practice, engineering as a field sees professional growth as learning in communities of practice [60]. In engineering, cultivating communities of practice is viewed as an effective way to develop and manage knowledge so that it can be shared among members of that community and new knowledge can be created $[51,63,64]$.

In the language socialisation perspective [65] novices progressively learn culturally appropriate communicative practices of a given community by interacting with more experienced members of that community. In doing so, Schieffelin and Ochs (1986) argue, novices develop competence in communicating within the context of a particular community and progressively move from guided or collaborative to independent action. As Sheri Sheppard et al. [2] argue, putting practice before theory in situated learning [60] allows for the kind of deep learning experience that mirrors professional practice, in which both technical and non-technical skills can develop [1, 6668]. As a result, this approach is viewed as fostering the culture of nurturing a future engineer who is not "just an expert technician" [2] but a well-rounded professional $[36,69]$.

In programs where no dedicated instruction is provided, linguistic socialisation is intended to take place in classroom and course-related activities [57, 70-74], intended to mirror professional practice [2, 36, 69]. The aim of these activities is to bring students together for the united purpose of completing a project and reap the rewards of good grades. Likely, the faculties' working assumption is that under these circumstances students feel motivated, if not compelled, to collaborate and interact. However, based on the findings of this research, the process of collaboration and interaction may not always be as automatic as one would like or intend. In the literature, several critics oppose taking a prescriptive approach to situated learning and using it to design structures of participation for classrooms and learning environments [61, 75-77].

To that end, engineering faculties are striving to translate the guiding principles of the situational learning construct into creating learning environments and opportunities for their students to develop the social and material practices of the engineering profession [61, 62, 78]. However, as Newstetter and Svinicki (2014) argue, engineering educators are "accomplished disciplinary experts rather 
than instructional designers" (p.29). Furthermore, research in engineering learning still lacks any systematic understanding and a solid framework of reference that "focuses on situativity and learning in engineering settings" [61].

\subsection{Non-Learning}

Instances were reported by research participants where linguistic and especially cultural problems surface and jeopardize the learning process. The term non-learning refers to any situation in which somebody has a possibility to learn something but fails to do so [79]. The term is often used in a considerably broad sense to refer to situations in which some learning takes place, but this learning is incorrect, insufficient, distorted, not in accordance with what is expected or intended (Illeris, 2012). As Benson (1997) argues, instances of nonlearning can be attributed to several reasons. First, he argues, there may be "a clash" with the teaching approach. Second, the student may perceive what is being taught as irrelevant, as in the case when students have a poor understanding of work term placement as a unique context in which communication is key in ensuring success. Third, the student may have poor language aptitude and find it particularly challenging to understand or interact in a given language. This would be the case of standardized admission tests (TOEFL, IELTS etc.) providing inaccurate assessment. Lastly, the author contends, students may be "subject to wide-spread ignorance and neglect of their own cultural assumptions" (p.30).

Coexistence does not automatically lead to intercultural contacts $[80,81]$. This is a critical point, particularly if collocated in the context of most engineering faculties, that view students' learning in the sociocultural or situated perspective as a process of becoming a full participant in a community of practice [62] of professional engineers [78]. Importantly, as suggested by interviewees, in many instances non-learning goes undetected and is left unaddressed.

Work term placements provide a testing ground where student's communication competence is evaluated as much as learning ground where the student is expected to grow as an effective communicator. Approached in this manner, research may lead to a timely identification of systemic gaps in students' preparation and help uncover instances of non-learning as they occur. In other words, the rather capillary investigation of academic and professional learning environments that begun with the research drawn in this paper has the potential to reveal those factors that act as barriers and as facilitators to students learning the communication competence essential for their professional success leading up to graduation, at set points along the program continuum.

Findings suggest that both contextual and individual barriers and facilitators exist. Examples of contextual factors include the intercultural sensitivity and openness of a student's peers, the willingness to accommodate students and the encouragement of work term supervisors. In the workplace, findings confirm, a student's ability to communicate effectively plays a pivotal role in the creation of opportunities for social interaction [10, 82, 83 ], and in the execution of daily professional exchanges [84]. Everyday conversations, small talk, humour can also have a big impact on how someone is perceived by colleagues $[85,86]$. It may have a significant effect on the integration and socialisation processes of a student, impacting not only her learning potential but the overall quality of the co-op experience for both the individual and the company.

Among individual factors, international students' selfsegregation on campus and in the workplace. As Chen argues [87], lack of mastery of the English language compromises individual's desire and intention to communicate, likely interfering with learning various aspects of life in the host country, including access to essential employment information. Existing research contends that an international student may subjectively choose whether and to what extent to embrace the culture of the host country $[10,12,14,82,88]$, whereby a student decide not to engage in behaviour that violates or conflicts with his or her personal values and beliefs [12]. As Molinsky observes, such willingness varies depending on the situation and the purpose of the interaction. Therefore, he contends, research that focuses on the process of acculturation would be better served by the adoption of a situational approach rather than the widely adopted U-curve [89] or the Berry's dual identification models [90].

Lastly, the effects on learning and non-learning of intercultural interactions among students of different languages, races, ethnicities, or genders, built on the premise that if students do not actually interact with one another and avoid working together, the benefits of diversity may be lost [see e.g. 91, 92-95]. Patterns of intercultural interactions in academic as well as workplace contexts may have a significant impact on the competence-building capacity at both individual and team levels. Therefore, they should be taken into account where competence-building participation in a learning environment may be curtailed. 


\section{CONCLUSIONS}

The research referenced in this paper generated a number of implications for practice, for policy, as well as suggestions for future research in the field of engineering communication education. Since the completion of that work, steps have been taken to reconcile the theory and practice examined in that research into a comprehensive framework of reference designed on the communication requirements of the pre-graduation engineering profession in Canada. The framework is conceived to provide a comprehensive and integrated structure capable of supporting the learning, the teaching, and the assessment of professional communication to engineering students. To that end, the framework is built on the premise that coop engineering students communicate in a range of reallife professional scenarios and contexts that vary based on the type of job and level of seniority. Those scenarios and contexts provide the backdrop against which a student's (in)ability to communicate effectively can and need to be observed as performance of communication.

Compatibility with the organic and individualized process of learning described above is the key requirement of the framework. Accordingly, the framework is being designed to accommodate the scaffolding of coordinated educational initiatives, opportunities for coaching and mentoring inside and outside academia, alongside a student's self-directed learning. Assessment is at the centre of the framework, considering the urgent need that exists for strategies and instruments that allow the continual monitoring of progress. Specifically, however, its approach to assessment will reflect a shift from practices that are summative, quantitative, deficit-based, prescriptive, expert-centred and static toward a more realistic process-centred model of learning. Accordingly, the assessment practices supported in this framework are characterized as being more formative, qualitative, strengths-based, descriptive, trainee/workplace- centred and fluid. Formal assessment and student's selfassessment coexist in this framework. They are intended and designed to complement each other.

Building on the theoretical construct that underpinned the interpretation of the research findings related in this paper, the framework is being developed within the theoretical construct of communicative competence [58, 96-100], as applied in the Common European Framework of Reference for Languages: Learning, teaching, assessment [101, 102]. The CEFR is a widely adopted internationally accredited scale of proficiency in the European languages. Accordingly, it functions as framework of reference and source of common standards/ criteria for assessing language outcomes that are discipline- and context- specific.
The CEFR is leaner-centred, task-oriented, and outcomebased. Working with the CEFR it becomes possible to identify and define the language tasks that describe what the student is expected to be able to do with the language to be considered adequately competent in communication while working in a specific professional role and/or context. In the literature, language tasks are referred to as 'performance descriptors' or 'Can Do" descriptors and are grouped to reflect performance in each of the four language skills (speaking, listening, writing, reading) and in four specific areas of competence in which workplace communication takes place: interaction, information, instructions, suasion (getting things done). Can Do descriptors are readily transferable to pedagogical initiatives, particularly in the preparation of rubrics or as support in the creation of learning outcomes. They are also used as benchmarks for assessment and selfassessment.

The development of this framework has the potential to significantly improve our ability to monitor and strengthen the communication competence of current and future engineering professionals in Canada. It has the characteristics to deliver integrated learner-centred applications in an efficient and economical way. It is scalable to diverse cohorts, contents, contexts, languages, and is applicable to a wide range of initiatives. Because of its rigorous theoretical structure, the framework can serve as a reference for the building and assessment of communication competence of both international and domestic engineering students who, reportedly, experience the same challenges erroneously believed to be a prerogative of their international peers. Perhaps most importantly, it provides a viable and robust starting point to bridge the gap between engineering education and professional practice by contributing to the formation of a well-rounded professional engineer.

\section{References}

[1] A. Colby and W. M. Sullivan, "Formation of Professionalism and Purpose: Perspective from the Preparation for the Professions Program," $U$. St. Thomas LJ, vol. 5, p. 404, 2008.

[2] S. Sheppard, K. Macatangay, A. Colby, and W. Sullivan, Educating engineers: Designing for the future of the field. San Francisco, CA: JosseyBass 2008.

[3] J. McMasters and N. Komerath, "BoeingUniversity Relations-A Review and Prospects for the Future," in Proc. ASEE Annual Conf. \& Expo, 2005.

[4] J. McMasters, "Thoughts on the Engineer of 2020," in "The Future of Engineering, Science and Mathematics: Who Will Lead?" A

Conference on the 50th Anniversary of Harvey 
Mudd College,, Claremont, California. January 14, 2006, 2006.

[5] NAE, The Engineer of 2020: Visions of Engineering in the New Century: The National Academies Press, 2004.

[6] NAE, "Educating the Engineer of 2020: Adapting Engineering Education to the New Century," The National Academies Press 9780309096492, 2005.

[7] NAE, Educating Engineers: Preparing 21st Century Leaders in the Context of New Modes of Learning: Summary of a Forum: The National Academies Press, 2013.

[8] E. Eyre, "Employability skills do not create equality, says research," Training Journal, pp. 13-13, 2011.

[9] M. Javidan, M. Teagarden, and D. Bowen, "Making It Overseas," Harvard Business Review, vol. 88, pp. 109-113, 2010.

[10] H. Anant, "Interpersonal Perceptions Within Organizations: An Exploratory Study," IUP Journal of Soft Skills, vol. 4, pp. 34-47, 2010.

[11] A. Molinsky, "Cross-Cultural Code-switching: The Psychological Challenges of Adapting Behaviour in Foreign Cultural Interactions," Academy of Management Review, vol. 32, pp. 622-640, 2007.

[12] A. Molinsky, "A Situational Approach for Assessing and Teaching Acculturation," Journal of Management Education, vol. 34, pp. 723-745, 2010.

[13] A. E. Munley, "Culture Differences in Leadership," IUP Journal of Soft Skills, vol. 5, pp. 16-30, 2011.

[14] K. V. Vinay, "The Pursuit of Values," ICFAI Journal of Soft Skills, vol. 3, pp. 52-57, 2009.

[15] S. Banerjee, "Target Group and Communication," ICFAI Journal of Soft Skills, vol. 3, pp. 18-24, 2009.

[16] B. Mishra, "Role of Paralanguage in Effective English Communication," ICFAI Journal of Soft Skills, vol. 3, pp. 29-36, 2009.

[17] V. Rajini, "Accent Neutralization For Effective Communication," IUP Journal of Soft Skills, vol. 3, pp. 45-49, 2009.

[18] S. Vandermeeren, "Foreign language need of business firms," in Second language needs analysis: Cambridge Univ Pr., M. H. Long, Ed., ed: Cambridge Univ Pr., 2005.

[19] D. Pons, "Optimising Employability: The transition from university to industry for engineering graduates," Journal of Adult Learning (Aotearoa New Zealand), vol. 40, pp. 4-35, 2012.

[20] T. E. Pinelli and C. W. Hall, "Collaborative Educational Experiences through Higher
Education-Industry Partnerships," in Presentation Handout for conference paper presented at the ASQ 2012 Advancing the STEM Agenda Conference at University of WisconsinStout, 2012, pp. 16-17.

[21] M. K. Schuurman, R. N. Pangborn, and R. D. McClintic, "The influence of workplace experience during college on early post graduation careers of undergraduate engineering students," Women in Engineering ProActive Network, 2005.

[22] M. K. Schuurman, R. N. Pangborn, and R. D. McClintic, "Assessing the Impact of Engineering Undergraduate Work Experience: Factoring in Pre-work Academic Performance," Journal of Engineering Education, vol. 97, pp. 207-212, 2008.

[23] R. K. Yin, Case study research: Design and methods, 4 ed. Los Angeles, CA: Sage publications, INC, 2009.

[24] S. B. Merriam, Qualitative Research and Case Study Applications in Education. Revised and Expanded from" Case Study Research in Education.". San Francisco: Jossey-Bass., 1998.

[25] B. G. Glaser and A. L. Strauss, The discovery of grounded theory: Strategies for qualitative research. Chicago, IL: Aldine de Gruyter Pub. Co, 1967.

[26] J. J. Gumperz, "The speech community," in Linguistic anthropology: A reader. vol. 1, A. Duranti, Ed., ed, 1968, pp. 66-73.

[27] J. J. Gumperz, "Interactional Sociolinguistics: A Personal Perspective," The handbook of discourse analysis, vol. 18, p. 215, 2003.

[28] J. J. Gumperz, "Discourse strategies: Studies in interactional sociolinguistics," Nev York. Cambridge University, 1982.

[29] K. Kokhan, "An argument against using standardized test scores for placement of international undergraduate students in English as a Second Language (ESL) courses," Language Testing, 2013.

[30] K. Kokhan, "Investigating the possibility of using TOEFL scores for university ESL decision-making: Placement trends and effect of time lag," Language Testing, vol. 29, pp. 291308, April 1, 20122012.

[31] S. Vinz, "Playing the TOEFL Game at SCSU," Linguistic Portfolios, vol. 1, p. 17, 2013.

[32] J. Fox, "Moderating top-down policy impact and supporting EAP curricular renewal: Exploring the potential of diagnostic assessment," Journal of English for Academic Purposes, vol. 8, pp. 2642, 2009.

[33] B. Bridgeman, D. Powers, E. Stone, and P. Mollaun, "TOEFL iBT speaking test scores as 
indicators of oral communicative language proficiency," Language Testing, vol. 29, pp. 91108, 2012.

[34] M. E. Malone, "Test review: Canadian Academic English Language (CAEL) Assessment," Language Testing, vol. 27, pp. 631-636, October 1, 20102010.

[35] D. Philpott, K. Kennedy, and M. Greene, "Strengthening the Value Chain: Supporting International Students and Building Intercultural Competence at Memorial University.," Memorial University of Newfoundland, St. John's, NL2014.

[36] M. Borrego and J. Bernhard, "The emergence of engineering education research as an internationally connected field of inquiry," Journal of Engineering Education, vol. 100, pp. 14-47, 2011.

[37] S. Sheppard, K. Macatangay, A. Colby, and W. M. Sullivan, Educating engineers: Designing for the future of the field: Jossey-Bass San Francisco, CA, 2009.

[38] (CLE) Subcommittee on Attributes and Competencies, "Graduate Attributes at the University of Alberta. Final report (Draft)," University of Alberta2013.

[39] N.A.E., Educating Engineers: Preparing 21st Century Leaders in the Context of New Modes of Learning: Summary of a Forum. Washington D.C.: The National Academies Press, 2013.

[40] N.A.E., "Educating the Engineer of 2020: Adapting Engineering Education to the New Century," The National Academies Press, Washington D.C. 9780309096492, 2005.

[41] N.A.E., "The Engineer of 2020: Visions of Engineering in the New Century," The National Academies Press, National Academy of Engineering, Washington D.C. 9780309091626 , 2004.

[42] CEAB-Canadian Engineering Accreditation Board, "Accreditation criteria and procedures," Engineers Canada, Ottawa, ON07 October 2014 2013.

[43] C.C.L.B., "Canadian Language Benchmarks: ESL for Adult Literacy Learners (ALL)," Centre for Canadian Language Benchmark, Ottawa, ON2015.

[44] T. Gillen, "How do we measure our employees' soft skills?," People Management, vol. 15, pp. 33-33, 2009.

[45] T. M. Kantrowitz, "Development and construct validation of a measure of soft skills performance," Doctor of Philosophy, School of Psychology. , Georgia Institute of Technology, 2005.
[46] C. Kovach, "Investing in Enabling skills," vol. 8, pp. 50-56, 2009.

[47] D. Sethi and M. Seth, "Interpersonal Communication: Lifeblood of an Organization," IUP Journal of Soft Skills, vol. 3, pp. 32-40, 2009.

[48] A. Fuller and L. Unwin, "Learning as Apprentices in the Contemporary UK Workplace: creating and managing expansive and restrictive participation," Journal of Education \& Work, vol. 16, pp. 407-426, 2003.

[49] C. Hodgkinson-Williams, H. Slay, and I. Siebörger, "Developing communities of practice within and outside higher education institutions," British Journal of Educational Technology, vol. 39, pp. 433-442, 2008.

[50] S. Wagenaar and J. Hulsebosch, "From 'A Meeting' To 'A Learning Community'," Group Facilitation: A Research \& Applications Journal, vol. 9, pp. 14-36, 2008.

[51] E. Wenger, R. A. McDermott, and W. Snyder, Cultivating communities of practice: A guide to managing knowledge. Boston, MA: Harvard Business Press, 2002.

[52] S. Allcorn and L. Godkin, "Dealing with organizational inertia: psychoanalytical insight and instruction," Competitiveness Review, vol. 18, pp. 378-387, 2008.

[53] K. Nielsen, "Scaffold instruction at the workplace from a situated perspective," Studies in Continuing Education, vol. 30, pp. 247-261, 2008.

[54] J. Yandell and A. Turvey, "Standards or communities of practice? Competing models of workplace learning and development," British Educational Research Journal, vol. 33, pp. 533550, 2007.

[55] C. Zimitat, "Capturing community of practice knowledge for student learning," Innovations in Education \& Teaching International, vol. 44, pp. 321-330, 2007.

[56] M. C. Paretti, L. D. McNair, and J. A. Leydens, "Engineering Communication," in The Cambridge Handbook of Engineering Education Research, A. Johri and B. Olds, Eds., ed New York, NY: Cambridge University Press, 2014, pp. 601-632.

[57] P. A. Duff, "Language Socialization, Higher Education, and Work," in Encyclopedia of Language and Education, N. Hornberger, Ed., ed Boston, MA: Springer US, 2008, pp. 257-270.

[58] D. Hymes, "On communicative competence," in Sociolinguistics, J. B. Pride and J. Holmes, Eds., ed Harmondsworth, England: Penguin Books, 1972, pp. 269-293. 
[59] J. S. Brown, A. Collins, and P. Duguid, "Situated cognition and the culture of learning,"

Educational researcher, vol. 18, pp. 32-42, 1989.

[60] J. Lave and E. Wenger, Situated learning: Legitimate peripheral participation. New York: Cambridge University Press, 1991.

[61] A. Johri, B. M. Olds, and K. O'Connor, "Situative frameworks for engineering learning research," in Cambridge Handbook of Engineering Education Research, A. Johri and B. Olds, Eds., ed New York: Cambridge University Press, 2014, pp. 47-66.

[62] W. C. Newstetter and M. D. Svinicki, "Learning theories for engineering education practice," in Cambridge handbook of engineering education research, A. Johri and B. Olds, Eds., ed New York: Cambridge University Press, 2014, pp. 2946.

[63] J. S. Goldberg and S. R. Goldberg, "New training method boosts productivity," Journal of Corporate Accounting \& Finance (Wiley), vol. 15, pp. 75-81, 2004.

[64] L. Lindkvist, "Knowledge Communities and Knowledge Collectivities: A Typology of Knowledge Work in Groups," Journal of Management Studies, vol. 42, pp. 1189-1210, 2005.

[65] B. B. Schieffelin and E. Ochs, "Language socialization," Annual review of anthropology, vol. 15, pp. 163-191, 1986.

[66] V. K. Gokuladas, "Technical and non-technical education and the employability of engineering graduates: an Indian case study," International Journal of Training \& Development, vol. 14, pp. 130-143, 2010.

[67] N. Komerath and M. D. Maughmer, "Educating the aerospace engineer of 2016," in 2005 ASEE Annual Conference \& Exposition: The Changing Landscape of Engineering and Technology Education in a Global World, 2005, p. 2005.

[68] The Conference Board of Canada. (2012, 22, April 2012). Employability Skills 2000+.

Available: http://www.conferenceboard.ca/topics/education/ learning-tools/employability-skills.aspx

[69] M. Besterfield-Sacre, M. F. Cox, M. Borrego, K. Beddoes, and J. Zhu, "Changing engineering education: Views of US faculty, chairs, and deans," Journal of Engineering Education, vol. 103, pp. 193-219, 2014.

[70] N. Morita, "Discourse socialization through oral classroom activities in a TESL graduate program," Tesol Quarterly, pp. 279-310, 2000.

[71] N. Morita and M. Kobayashi, "Academic discourse socialization in a second language," in
Encyclopedia of language and education: Language socialization. vol. 8, P. A. Duff and N. Hornberger, Eds., ed Boston,: Springer, 2008, pp. 243-255.

[72] P. A. Duff, "Language socialization into academic discourse communities," Annual Review of Applied Linguistics, vol. 30, pp. 169192, 2010.

[73] K. Silseth and H. Arnseth, "Frames for learning science: analyzing learner positioning in a technology-enhanced science project," Learning, Media and Technology, vol. 41, pp. 396-415, 2016.

[74] L. Mondada, "Challenges of multimodality: Language and the body in social interaction," Journal of Sociolinguistics, vol. 20, pp. 336-366, 2016.

[75] J. G. Greeno, "On claims that answer the wrong questions," Educational researcher, vol. 26, pp. 5-17, 1997.

[76] J. G. Greeno, "Learning in activity," in The Cambridge handbook of learning sciences, $\mathrm{K}$. Sawyer, Ed., ed New York, NY: Cambridge University Press, 2006, pp. 79-96.

[77] J. G. Greeno and C. van de Sande, "Perspectival understanding of conceptions and conceptual growth in interaction," Educational Psychologist, vol. 42, pp. 9-23, 2007.

[78] T. A. Litzinger, L. R. Lattuca, R. G. Hadgraft, and W. C. Newstetter, "Engineering Education and the Development of Expertise," Journal of Engineering Education, vol. 100, pp. 123-150, 2011.

[79] K. Illeris, "Non-learning," in Encyclopedia of the Sciences of Learning, N. M. Seel, Ed., ed Boston, MA: Springer US, 2012, pp. 2478-2479.

[80] M. Otten, "Intercultural Learning and Diversity in Higher Education," Journal of Studies in International Education, vol. 7, pp. 12-26, March 1, 20032003.

[81] H. Spencer-Oatey and D. Dauber, "How internationalised is your university? From structural indicators to an agenda for integration.," presented at the British Council Going Global 2015,, Queen Elizabeth Conference Centre, London, UK, 2015. C. Chamberlin-Quinlisk, "Language learner/native speaker interactions: exploring adaptability in intercultural encounters," Intercultural Education, vol. 21, pp. 365-377, 2010.

[83] J. Holmes, "Talking English from 9 to 5: challenges for ESL learners at work," International Journal of Applied Linguistics, vol. 10, pp. 125-140, 2000. 
[84] J. Holmes and N. Riddiford, "From classroom to workplace: tracking socio-pragmatic development," ELT Journal: English Language Teachers Journal, vol. 65, pp. 376-386, 2011.

[85] J. Holmes, "When small talk is a big deal: Sociolinguistic challenges in the workplace," Second language needs analysis, pp. 344-372, 2005.

[86] J. Holmes and M. Marra, "Having a laugh at work:: how humour contributes to workplace culture," Journal of Pragmatics, vol. 34, pp. 1683-1710, 2002.

[87] C. P. Chen, "Career Guidance with Immigrants," in International Handbook of Career Guidance, ed, 2008, pp. 419-442.

[88] A. Molinsky, Global Dexterity: How to Adapt Your Behavior Across Cultures Without Losing Yourself in the Process: Harvard Business Review Press, 2013.

[89] S. Lysgaard, "Adjustment in a foreign society: Norwegian Fulbright grantees visiting the United States," International Social Science Bulletin, vol. 7, pp. pp. 45-51, 1955.

[90] J. W. Berry, "Conceptual approaches to acculturation," in Acculturation: Advances in theory, measurement and applied research, $\mathrm{K}$. M. Chun, P. B. Organista, and G. Marin, Eds., ed Washington, DC: American Psychological Association, 2003, pp. 17-36.

[91] L. Engle and J. Engle, "Assessing Language Acquisition and Intercultural Sensitivity Development in Relation to Study Abroad Program Design," Frontiers: The Interdisciplinary Journal of Study Abroad, vol. 10, pp. 219-236, 2004.

[92] B. F. Freed, "An overview of issues and research in language learning in a study abroad setting," Frontiers: The Interdisciplinary Journal of Study Abroad, vol. 4, pp. 31-60, 1998.

[93] A. Llanes and C. Muñoz, "A short stay abroad: Does it make a difference?," System, vol. 37, pp. 353-365, 2009.

[94] J. Rees and J. Klapper, "Analysing and evaluating the linguistic benefit of residence abroad for UK foreign language students," Assessment \& Evaluation in Higher Education, vol. 32, pp. 331-353, 2007.

[95] T. R. Williams, "Exploring the Impact of Study Abroad on Students' Intercultural Communication Skills: Adaptability and Sensitivity," Journal of Studies in International Education, vol. 9, pp. 356-371, Winter 2005 2005.

[96] M. Canale and M. Swain, "Theoretical bases of communicative approaches to second language teaching and testing," Applied linguistics, vol. 1, 1980.

[97] M. Canale, "From communicative competence to communicative language pedagogy," in Language and communication. vol. 1, J. C. Richards and R. W. Schmidt, Eds., ed London ; New York: Longman, 1983, pp. 1-47.

[98] L. F. Bachman and A. Palmer, "Language assessment in practice," ed: Oxford: Oxford University Press, 2010.

[99] M. Celce-Murcia, Z. Dörnyei, and S. Thurrell, "Communicative competence: A pedagogically motivated model with content specifications," Issues in Applied linguistics, vol. 6, pp. 5-35, 1995.

[100] M. Celce-Murcia, "Rethinking the role of communicative competence in language teaching," in Intercultural language use and language learning, ed Dordrecht: Springer, 2007, pp. 41-57.

[101] Council of Europe. (2014, January). Common European Framework of Reference for Languages: Learning, Teaching, Assessment (CEFR). Available: http://www.coe.int/t/dg4/linguistic/cadre1_en.as p

[102] Council of Europe, "Common European Framework of Reference for Languages: Learning, Teaching, Assessment (CEFR). Companion Volume with new Descriptors.," Language Policy Programme Education Policy Division Education Department, Strasbourg.2018. 